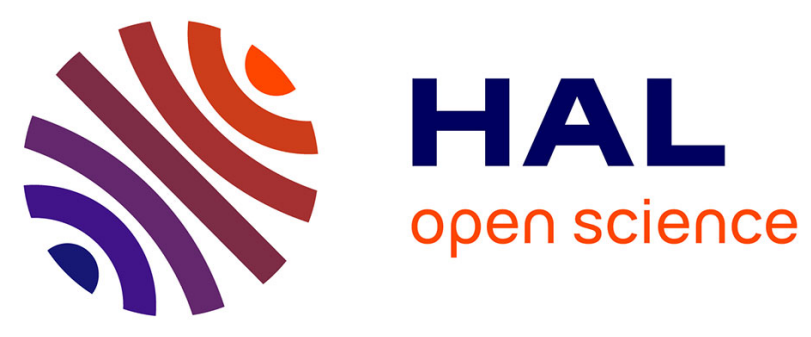

\title{
Belief and Performativity
}

Alda Mari

\section{To cite this version:}

Alda Mari. Belief and Performativity. Aspects of Tenses, Modality, and Evidentiality, 2021, 10.1163/9789004468184_011. halshs-02870102

\section{HAL Id: halshs-02870102 \\ https://shs.hal.science/halshs-02870102}

Submitted on 16 Jun 2020

HAL is a multi-disciplinary open access archive for the deposit and dissemination of scientific research documents, whether they are published or not. The documents may come from teaching and research institutions in France or abroad, or from public or private research centers.
L'archive ouverte pluridisciplinaire HAL, est destinée au dépôt et à la diffusion de documents scientifiques de niveau recherche, publiés ou non, émanant des établissements d'enseignement et de recherche français ou étrangers, des laboratoires publics ou privés. 


\title{
Belief and Performativity
}

\author{
Alda Mari \\ Institut Jean Nicod CNRS/ENS/EHESS/PSL
}

March 2020

This is a version corresponding to a talk given at Chronos 13, in 2018 and which is to appear in the Cahiers Chronos.

\section{$1 \quad$ Belief and assertion}

According to the influential view stemming from the work of Frege (1918), the speech act of assertion is the result of the communicative intention of making visible some internal state or thought. In Frege's view, asserting is making a BELIEF known. ${ }^{1}$ Language provides a handle to investigate the nature of BELIEF, and, on the assumption that the verb believe (and its correspondents across languages) is the reflex of the notion of BELIEF, the assertion of the "believe that $p^{2 \text { " }(~} p=$ 'it is raining') (1-a) and the assertion of $p$ (1-b) would amount to one and the same act (for recent discussion, see Lauer, 2013; Howthorne et al. 2016).
a. I believe that it is raining.
b. It is raining

In support of this view, the following so-called Moorean paradoxical sentences show that $\mathrm{B} p$ ('believe $p$ ) and $\mathrm{A} p$ ('assert $p$ ') are equivalent. (2-a) shows that it is impossible to assert $\mathrm{B} p$ while denying the assertion that $p$. (2-b) shows that it is impossible to assert $p$, while denying $\mathrm{B} p$.

a. I believe that it rains, \#but it does not rain.

b. It rains, \#but I do not believe that it rains.

This first set of data would show that belief statements and bare assertion have a comparable strength and that belief statements are as 'strong' as assertions, indicating full commitment to the truthfulness of the prejacent.

On the other hand, the minimal pair in (3) shows that BELIEF, as per its lexicalization believe, is weaker than bare assertion, given the possibility of the 'I am not certain' continuation with the latter only (Hawthorne et al. 2016). If $\mathrm{B} p$ and $p$ were of a comparable force, they would both be incompatible with the not-C $p$ continuation (where not-C $p$ is ' I am not certain that $p$ ').

a. It is raining, \#but I am not certain that it is raining.

b. I believe that it is raining, but I am not certain that it is raining.

The question thus arises of whether belief statements are strong as or weaker than assertion and what this tell us about BELIEF more generally. ${ }^{3}$

\footnotetext{
${ }^{1}$ We use small caps for notions (e.g. BELIEF), capital letters for cross-linguistic expressions (e.g. BELIEF), and italics for expressions in a given language (e.g. credere).

${ }^{2} p$ is called the prejacent when embedded under a modal element - a modal verb or an attitude.

${ }^{3}$ Let us note right from the bat that posing the question in these terms might be somehow misleading. Indeed, it is unclear that knowledge and belief are norms for assertion. It is a daily habit to assert without fully believing $p$ let alone without knowing $p$. When the question is posed of how strong belief is in comparison with the bare assertion, the theoretician has in mind the idealized assertions justified by full belief and, most importantly sincere, conceiving it as the most reliable
} 
This paper adds new elements to the debate from the standpoint of language, grounding the discussion in the lexicalizations BELIEF and specifically by considering mood choice in languages that allow both indicative and subjunctive under BELIEVE-predicates. It thus tackles the question of the strength of BELIEF by considering different cross-linguistic lexicalizations of this concept.

Cross-linguistically, the literature has traditionally adopted the Hintikkean semantics according to which BELIEVE predicates reveal 'credence' or full epistemic commitment to the truthfulness of prejacent (a.o. Farkas, 1985,2003; Giannakidou, 1999; Villalta, 2008; Anand and Hacquard 2013; Gosselin, 2015,2016).

Hintikka semantics for believe:

All worlds in the doxastic space of the attitude holder are $p$ worlds. ${ }^{2}$

By uttering 'I believe that it is raining', the speaker signals in all worlds that are compatible with the mental state it is raining, and in this way, believe expresses certainty in $p$. The set of worlds compatible with what the speaker believes is homogeneous and homogeneity in a belief state reveals certainty.

According to most of the theoreticians of mood (a.o. Farkas, 1985,2003; Giannakidou, 1999; Homer, 2007; Villalta, 2008; Anand and Hacquard 2013; Portner and Rubinstein, 2013; Gosselin, 2015,2016 ), the subjunctive is triggered by uncertainty. Uncertainty is conceived as a partitioning in the mental state, or, in terms of possible worlds, as a partition in the set of worlds compatible with what the speaker believes.

Since the Hintikkean doxastic space is homogeneous, BELIEVE-predicates are considered to be indicative selectors across languages. Italian, however, licenses both subjunctive and indicative under credere (believe) - with an overwhelming preference for the subjunctive.

$$
\begin{array}{ll}
\text { Paolo crede che Maria sia/è } & \text { incinta. } \\
\text { Paolo believes that Mary be.SUBJ.3SG/IND.3SG pregnant. } \\
\text { Paolo believes that Mary is pregnant. }
\end{array}
$$

We consider mood shift as key entry into the semantics of expressions of BELIEF, which allows us to see a distinction between private and public attitudes. Private attitudes are such that the content is not deemed to become common ground. Public attitudes are such that the content of the attitude can become common ground.

While the distinction between private and public BELIEFS is not new (see most notably Gunlogson, 2001), the novelty here is that the BELIEF verbs are equipped with update instructions that make them akin to speech acts. In this way, we revisit the dichotomous Hamblin distinction (Hamblin, 1960) between public and private commitments as introduced by speech acts and attitudes respectively. ${ }^{4}$

We thereby also propose a new distinction between two different types of belief statements as fulfilling different discourse functions (adding or not preference for $p$ in the common ground).

Finally, we argue that the concept BELIEF has a variety of possible lexicalizations, and ultimately it can be itself polymorphic in such a way that seemingly contradictory moorean paradoxes can arise.

The paper contains three main sections discussing the data (section 2), presenting the analysis (section 3) and deriving the predictions (section 3). Section 4 concludes.

\section{The solipsistic - inquisitive distinction: data}

In Italian, the use of the subjunctive is pervasive with non-factive epistemic attitudes, escaping a wellestablished cross-linguistic generalization according to which belief predicates trigger the indicative (Farkas, 1985;2003 Giannakidou 1999; Farkas 2003; Villata, 2008; Anand and Hacquard, 2013;

manifestation of the speaker's epistemic state. In this respect, the bare assertion establishes the norm of strength, by setting the highest possible standard of commitment to the truthfulness of the prejacent on behalf of the assertor. While this is certainly a simplification, it is a simplification that allows us to dig a bit deeper in the semantics of the belief and to tease out some important differences between BELIEF and assertion which we will be more at ease to refine once we have established a clear framework to compare them based on empirical evidence.

${ }^{4}$ Our goal here is not to provide a theory of mood choice, and mood is only instrumental to revealing a distinction between two different types of BELIEFS. 
Gosselin, 2015,2016; see for pragmatic account of Italian subjunctive with belief predicates, Quer, 1998; Farkas, 2003; Schlenker, 2007; Portner and Rubinstein, 2013).
a. Paolo crede che Maria sia
arrivata.
Paolo believes that Maria be.SUBJ.3SG
arrived.
Paolo believes that Mary has arrived.
b. Paolo pensa che Maria sia arrivata.
Paolo thinks that Maria be.SUBJ.3SG arrived.

One straightforward explanation would posit that belief in Italian conveys uncertainty, and that credere would mean 'I believe but I am not sure' (see Rhis, 2013). The 'I am not sure' could be argued to be an implicature, and indeed Homer (2007) has proposed an account along these lines. This proposal, however, stumbles on mood distributions with predicates of certainty as shown in (7).
a. Giovanna è sicura che Maria sia
incinta.
Giovanna is certain that Mary be.SUBJ.3SG pregnant.
Joanne is certain that Mary is pregnant.
b. Giovanna è convinta che Maria sia incinta.
Giovanna is convinced that Mary be.SUBJ.3SG pregnant.
Joanne is convinced that Mary is pregnant.

To establish the distinction between private and public belief, we propose a detour through fictional attitudes, which provide a useful handle to understand the possible meanings and uses of BELIEVE-predicates.

\subsection{Private and public fictional predicates}

Fictional attitudes like DREAM, IMAGINE are consensually described as selecting the indicative (e.g. Giorgi and Pianesi, 1996; Giannakidou, 1999; Farkas, 2003). They are claimed to trigger a homogeneous modal base, consisting of $p$-dreaming/imagining worlds. The usual semantics mimics the semantics for Hintikka belief, and most if not all theoreticians of mood would agree on the following analysis in (8) (Giannakidou, 1998).

Fictional attitudes.

All worlds in the fictional modal base of the attitude holder are $p$ worlds.

Unexpectedly, fictional predicates can also license the subjunctive in Italian (see Mari, 2016; Giannaidou and Mari, in press, Mari and Portner, 2019).

$$
\begin{array}{lll}
\text { Immagino } & \text { che Maria sia } & \text { incinta oramai. } \\
\text { Imagine.IND.1SG } & \text { that Mary be.SUBJ.3SG } & \text { pregnant by-now. }
\end{array}
$$

I imagine that Mary is pregnant by-now.

The use of the subjunctive can trigger a conjectural interpretation and in this case, the sentence states that the speaker does not know whether $p$ is true, but she is reporting that in worlds that are compatible with what she knows and which comply with her imagination, Mary is pregnant. One important feature of (9) is that whether Mary is pregnant or not can be known and settled as true or false in the common ground. This leads to set the following distinction.

(10) Solipsistic and inquisitive-IMAGINE (adapted from Mari, 2016).

a. Solipsistic-IMAGINE-sentences are true if and only if in all worlds compatible with the mental state of the assessor $p$ is true.

b. Inquisitive-IMAGINE-sentences are true if and only if p can be known 
the assessor does not know whether $p$ is true and

in all worlds compatible with the mental state of the assessor $p$ is true.

Generalizing cross-linguistically, and submitting that the verb imagine in English shares these two interpretations with the Italian immaginare, at a first approximation, it would be plausible to pose two different truth conditions for IMAGINE-sentences, which Mari 2016 distinguishes as solipsisticIMAGINE-sentences and inquisitive-IMAGINE-sentences. As with inquisitive-IMAGINE, truthfulness of $p$ matters. With pure imagination (solipsistic-IMAGINE), it does not. With this distinction in mind, we now turn to credere (believe).

\subsection{BELIEVE: Solipsistic and inquisitive distinction}

Mari 2016 proposes that there is a parallel difference between an solipsistic-credere as an indicative selector in Italian and an inquisitive-credere as a subjunctive selector. Solipsistic-credere sentences report an internal, solipsistic state (a credence) and that inquisitive-credere sentences report hypothesis about the truthiness of $p$ (a conjecture) of the attitude holder.

We now show that solipsistic-belief and inquisitive-belief differ in one important respect. Solipsistic-belief is blind to the knowability of $p$ (i.e. it does not require that $p$ be knowable), it is a pure expression of credence considered as a solipsistic thought. Inquistive-belief requires that $p$ be knowable in the context of utterance and conveys lack of knowledge about the truthfulness of $p$. To highlight the 'knowability' constraint on the use of inquistive-belief, we consider two contexts, in which $p$ is not settled and cannot be known. These two contexts are futurity and predicates of personal taste. If our hypothesis that the subjunctive deals with finding and establishing the truthfulness of $p$, specific accommodations are needed in order for the subjunctive to be operational in these two contexts.

\subsubsection{Subjunctive and futurity}

The non-deterministic view of future represents past and present as settled and the future as open (e.g. Thomason, 1998; Copley, 2002; Kaufmann, 2005; Mari, 2015; Giannakidou and Mari, 2018a). As a consequence, if $p$ is evaluated at a time that follows the time at which the attitude holds, it cannot be assigned a truth value (see McFarlane, 2005), and cannot be known (see Giannakidou and Mari 2018a for a recent discussion about predictions). The deterministic view of future represents future just as determined as settled as past and present but acknowledges that the future cannot be known. The future, under any theory is un-knowable.

By accommodating plans and decisions, $p$ can be 'known' relative to those plans and decisions at the time at which the attitude holds (for simplicity we will from now on assume that this is the time of utterance) (see Copley, 2002). For instance, the sentence I will go to the party tonight is true now if and only if in all worlds that comply with my plans I go to the party tonight. Likewise, the truthfulness of $p$ can already be assessed at the time of utterance if the assessor has a sufficiently reliable body of evidence (Giannakidou and Mari, 2018). $p$, in that case, will be true relative to the epistemic modal base of the assessor.

We see in (11) that the subjunctive can be used unproblematically in a context where the time of evaluation of $p$ is in the future. Consider the following scenario. We are organizing a party and John is invited. Usually John does not come to parties, however, he is very much in love with Mary and Mary is coming for sure.

Crede che venga anche Gianni questa volta. (Mari 2016)

Believes that come.SUBJ.3SG also John this time.

She believes that John is coming too this time.

In some other contexts, though, the subjunctive is infelicitous. Consider the following minimal pair. My son has a tendency to forget stuff at school. My husband wants to buy him an expensive scarf and asks me whether it is a good idea, or whether I believe that he will lose it. 

a. Credo
che la
perderà.
(Mari, 2016)
Believe.PRES.1SG that that lose.FUT.IND.3SG
I believe that he will lose it.
b. Credo
che la perda.
Believe.PRES.1SG that that lose. SUBJ.3SG
I believe that he will lose it.

In (12) the indicative is the only possible choice. The following contrast also reveals that the subjunctive can be used only in those contexts where $p$ can be assigned a truth value at the time at which the attitude holds. Specifically, the truthfulness/falsity of $p$ in (13-a) can be assessed relatively to a plan (those of the Olympics committee). The truthfulness of $p$ cannot instead be assessed at the time of utterance in (13-b), if not by an expert (or anyone considering himself an expert) with knowledge sufficient to assess the truthfulness of $p$ at the time of utterance.
a. $\quad$ Crede che le
Olimpiadi si svolgano.
a Tokyo.
Believes that the Olympics REFL take place.SUBJ.3PL
at Tokyo.
She believes that the Olympics will take place in Tokyo.
b. (\#)Crede che la Francia perda, questa sera.
Believes that the France lose.SUBJ.3SG, this night.
She believes that France will lose, tonight.

Our conclusion will thus be that, if $p$ is not knowable, subjunctive with credere is less felicitous.

\subsubsection{Subjunctive and predicates of personal taste}

Across the variety of theories for predicates of personal taste $P$, theoreticians agree that there is no fact of the matter about $P$ (see in particular discussion in Lasersohn, 1995; Stephenson, 2007). When uttering (14), truth cannot be assessed simpliciter relative to the circumstances. There is no 'fact of the matter' of the soup being or not being tasty, and, once again, in this respect, $p$ cannot be known.

The soup is tasty.

As with futurity is it possible to accommodate some form of 'objectivity'. In particular, some criteria can be adopted for assessing the truthfulness of $p$ that the participant can share. These criteria will help them to together establish, in the common ground, whether $p$ is true or false. A group of friends is looking for a restaurant. One of them suggests:
a. Andiamo lì, credo
Let's go there, I believe it is good.
Go.IMP.1SG there, believe.IND.1SG that be.IND.3SG good.
b. Andiamo lì, credo che sia buono.
Go.IMP.1SG there, believe.IND.1SG that be.SUBJ.3SG good.
Let's go there! I believe that it is good!'

The statements in (15-a) and (15-b) rely on different types of evidence. By choosing the indicative the speaker indicates that his judgment relies on some internal perception (he has already eaten at that restaurant, he likes how it looks like, ...). The evaluation is subjective in a proper way, based on some visual experience or an experience of taste. This type of subjective judgment is incommensurate with one that could be expressed by other speakers. ${ }^{5}$ In choosing the subjunctive the speaker signals instead

\footnotetext{
${ }^{5}$ The debate on faultless disagreement was born with Aristotle and is still very active, in particular in the philosophical literature, which strives to account for the sources of subjectivity. It would be impossible to propose here a list of relevant works. The linguistic literature, instead, has mostly considered predicates of personal taste from the perspective of the evidential underpinnings of the subjective judgments, and the incommensurability of the evidential experience is an appealing notion, to which we would be willing to subscribe. However, regardless of what the explanation of the subjectivity
} 
that he is relying on some external evidence (15-b), that he has heard or read about the restaurant. In this case, some other source of knowledge, a more reliable one, is accommodated. $p$ can be 'known' relative to this body of knowledge and, relative to this type of evidence, the evaluations of the participants are commensurable with each other.

Note that the choice of the first person here is not random. The idea guiding our interpretation of indicative-credere is that it is akin to exclamatives, whereby a personal appreciation is being put forward (see e.g. Castroviejo, to appear, for an overview). Given the inscrutability of third person personal appreciation, third person examples are less revealing of the distinctions that we are attempting to settle here.

\section{Analysis}

Our analysis will articulate a semantic and a pragmatic dimension around the update instruction of the attitudes. We distinguish private and public attitudes and argue that, when public, the attitudes instruct to update the negotiation space with the semantic content of the attitude. This allows us to establish a distinction between two different types of BELIEVE-statements fulfilling two different types of discourse functions, one of which only consists in proposing $p$ for uptake. In this framework we will be able to understand the similarities and differences between BELIEVE-statements and bare assertions.

\subsection{The semantics of solispsistic and inquisitive belief}

Following Mari (2016), we posit a difference between two types of BELIEFs in the semantics. According to Mari (ibid.) and Giannakidou and Mari (in press), two solipsistic-BELIEF and inquisitive-BELIEF correspond to two different interpretations of BELIEF. By resorting to the standard tools in the analysis of mood, the difference would result in positing a doxastic space (or modal base) for the solipsistic-belief and a supplementary epistemic space (or modal base) for the inquisitive belief. Solipsistic belief would be a one layer belief (doxa only) conveying doxastic certainty, inquisitive belief would disentangle knowledge and doxa and convey lack of knowledge but doxastic certainty.

(16) Solipsistic and inquisitive-credere. To be completed.

a. Solipsistic-BELIEVE.

All doxastic worlds are $p$ worlds.

$b$. Inquisitive/conjectural-BELIEVE.

$\rightarrow$ Presupposes that $\mathrm{p}$ is knowable.

The attitude holder does not know whether $p$ is true.

All doxastic worlds are $p$ worlds.

The semantics of inquisitive-belief thus codes (i) knowability of $p$ and (ii) lack of knowledge besides (iii) signaling that the doxastic worlds of the attitude holder are all $p$ worlds. This accounts for the fact that subjunctive-belief is used in contexts where the interlocutors are striving to settle truthfulness of $p$. Knowledge thus matters, and not only the individual credences.

\subsection{The pragmatics and the update instructions of epistemic attitudes}

\subsubsection{Articulating public and private commitments.}

Moving to consideration of how knowledge is interactively built in conversations (Stalnaker, 1978; Roberts, 1996/2012), we submit that conjectural belief is chosen to raise a question, and thus revisit the meaning of attitudes - and BELIEVE in particular -, considering their contribution in attempting to update the common ground $C$ and more precisely, as we now argue, the negotiation space $N$.

might be, what matters for our demonstration here is that predicates of personal taste appeal to a notion of truth which cannot be 'objective', unless objectivity is overtly accommodated. 
We claim that representational/epistemic attitudes can contribute to both the private and the public (modal) spaces because, unlike pure bouletics, ${ }^{6}$ they are sensitive to the knowability of $p$, and thus to the possibility of establishing truth.

Both old and much recent work on speech acts has proposed fruitful revisitations of the notion of common ground, and, more broadly, of doxastic spaces (see e.g. Hamblin, 1970; Clark and Schaefer 1989; Frakas and Bruce, 2010; Ginzburg, 2011; Krifka, 2015). In particular, they have overcome the Stalnakerian view according to which the common ground shrinks as conversations unfold. According to Stalanker, each assertion of $p$ eliminates non- $p$ worlds, with conversations pursuing the goal of narrowing down the common ground to the actual world, thus establishing truth.

Several theoreticians now conceive the common ground as a space where issues or questions are solved (Roberts, 1996/2012) and proposals are made. With Farkas and Bruce (ibid.) we assume that for any given conversation, three spaces must be distinguished: a private space $s$, keeping track of the private beliefs, and a negotiation space $N$, which is a public space where proposals are made or questions are asked, and finally the common ground $C$, where ratified and mutually accepted propositions are stacked.

Negotiation spaces are supersets of common grounds (see also Portner, 2007). According to Farkas and Bruce (2010:88), assertions (by adding $p$ to $N$ ) project a future $C$ that includes the asserted proposition, whereas a question (by adding at least two alternatives to $N$ ) projects a set of $C \mathrm{~s}$, each containing only one of the possible answers to the question. This is a feature that we will maintain in our account, where negotiation spaces rather than the common grounds will play a role (in order to be added to the common ground dialogical moves are needed. For assertion, this dialogical move is ratification (which can amount to lack of objection); for questions, even biased, an answer from the addressee is needed; see discussion in Farkas and Bruce, 2010).

Our account considers the private and the public space as independent from each other. ${ }^{7}$ Overall, different interpretations of belief statements reveal different articulations between $s$ and $N$. The possibility of privately committing without publicly committing (or only partially publicly committing, i.e. the addition of both $p$ and not- $p$ to $N$ ) gives a handle to disentangle assertion and belief and makes a new case, besides lies, to separate the public and the private spheres of belief as not mutually entailing.

\subsubsection{Public and private attitudes}

Based on the distinction that Italian allowed us to draw, we assume that attitudes divide in two classes according to whether they are public or private.

Public attitudes are such that if $p$ is true, $p$ becomes necessarily common ground and is believed by all participants. As for belief, if subsequent to the utterance 'I believe that John is arriving', John arrives, the prejacent $p=$ 'John arrives' becomes common ground and is believed by all the participants in the conversation. Instead, for private attitudes even if $p$ becomes true, it is not necessarily endorsed by all participants. If one utters 'I want an ice-cream' and then buys himself an ice-cream, it does not follow that the other participants are in a state of wanting an ice-cream.

Prior to the verification of the truth of the prejacent, we claim that, with public attitudes, $p$ is presented for uptake. With private attitudes, it is not. More generally for attitudes the following distinction is proposed:

\footnotetext{
${ }^{6}$ It is a well-known fact that there are mixed cases of bouletic-epistemic predicates, like hope. These predicates also have a public use, which we do not discuss here.

${ }^{7}$ To shed some light on the difference between (1-a) and (1-b) we will abandon two generally held assumptions. The first assumption that we abandon is that $N$ and $C$ are subsets of the private space $s$ of (or doxastic commitments, see Farkas and Bruce 2010:86). With no further specifications, on this assumption, one cannot account for the fact that a belief is consistently held privately, without being held publicly. Let us assume that (1-a) states that $p$ is decided in $s$ (i.e it follows from $s$; e.g. Farkas, 1982,2003; Anand and Hacquard, 2015; Giannakidou 2016). If $N$ is a subset of $s$, then $p$ is also added to $N$. Moreover, for sincere assertions it is also assumed, as per Grice, that if $p$ is decided in $N$, then $p$ is decided in $s$ (see the 'perspective' section below). We also abandon this assumption.
} 
Private and Public attitudes.

a. PRIVATE attitudes: $p$ is not for uptake (e.g. want)

b. PUBLIC attitudes: $p$ is for uptake (e.g. believe)

One given attitude type, e.g. BELIEVE-predicates, can have different realizations both as private and as public. Italian credere is one such attitude.

Our new claim here is that attitudes have update instructions, just like assertions or imperatives. Our understanding of the solipsistic-conjectural distinction for credere is thus as follows:

\section{Solipsistic and Inquisitive-BELIEVE. Final.}

a. Solipsistic-BELIEVE

All worlds in the doxastic space $s$ of the attitude holder are $p$ worlds (= Hintikka belief)

b. Inquisitive-BELIEVE.

All worlds in the doxastic space $s$ of the attitude holder are $p$ worlds (= Hintikka belief)

$\&$ the attitude holder does not know whether $p$ is true

UPDATE INSTRUCTION: PRESENT $p$, where PRESENT is as in (23).

PRESENT: update the negotiation space $N$ with $p>$ not- $p$

In a context where participants strive to build a consensus around $p$, either $p$ or its negation has to make it into the common ground. Since the attitude holder does not know whether $p$ is true, $\mathrm{s} / \mathrm{he}$ is not in a position of adding $p$ itself in the negotiation space. Instead, $\mathrm{s} / \mathrm{he}$ can only add a preference for $p$.

Let us illustrate the proposal and start with WANT, a private attitude. Since there is no instruction to update the negotiation space, the private space is updated.

\begin{tabular}{|c|c|c|}
\hline WANT & Attitude & Update \\
\hline Semantics & $p>$ non- $p$ & \\
\hline Pragmatic & Attitude type: Private & Adds $p>$ non- $p$ to $s$ \\
\hline
\end{tabular}

Table 2: WANT

As for solipsistic-BELIEF, we have argued that the truthfulness of $p$ does not matter, and, in this case, the predicate expresses a mere credence of the attitude holders. As we noted, expressions of credence in the indicative are typically used in prayers. This is explained by the textual genre: prayers express a personal credence, and their content is not there for an uptake.

$$
\begin{aligned}
& \text { Io credo che esiste Dio } \\
& \text { I believe.IND.1SG that exists God } \\
& \text { I believe that God exists. } \\
& \text { https://www.chiesavaldesetrapani.com/ }
\end{aligned}
$$

The following table summarizes the proposal. The attitude gives no instruction to update the negotiation space, and, as a consequence, the private space is updated.

\begin{tabular}{|c|c|c|}
\hline SOLIPSISTIC BELIEF & Attitude & Update \\
\hline Semantics & $p$ & \\
\hline Pragmatic & Attitude type: Private & Adds $p$ to $s$ \\
\hline
\end{tabular}

Table 3: SOLIPSISTIC BELIEF

Inquisitive-BELIEVE proposes $p$ for an uptake; this is signaled by the update instruction associated with the public attitude, PRESENT, which urges an update to the negotiation space with a 
preference for $p$. Unlike the bare assertion, inquisitive-BELIEVE conveys that the speaker is not confident enough to just add $p$ to $N$. In other terms, she is not fully committed to $p$ publicly.

Note that the attitude holder (which in the first person is the speaker) is fully committed to $p$ privately.

\begin{tabular}{|c|c|c|}
\hline INQUISITIVE BELIEF & Attitude & Update \\
\hline & Layer 1: & \\
& $\begin{array}{c}\text { Presupposition: } p \text { \& not- } p \\
\text { (lack of knowledge) }\end{array}$ \\
& Layer 2: & \\
& Assertion: $p$ & \\
& (personal belief) & \\
Semantics & Attitude type: Public & Adds $p>$ non- $p$ to $N$ \\
\hline
\end{tabular}

Table 4: INQUISITIVE BELIEF

Inquisitive-belief, unlike private belief, is used informatively, as we discuss more at length in section 4.1 .

\subsection{Extension to immaginare}

As we have noted in section 2.1, immaginare and credere follow the same pattern. Recalling here the examples, we see that the use of the subjunctive can enhance a reading that we can classify as 'inquisitive', that it is to say, it conveys a conjecture about an actual state of affairs.

$$
\begin{aligned}
& \text { Immagino che tu sia } \quad \text { arrivato } \\
& \text { Imagine.PRES.1SG that you be.SUBJ.3SG arrived.SUBJ.3SG in late. } \\
& \text { I imagine that you were late. }
\end{aligned}
$$

To obtain the pure imagination reading, the indicative can be used (the indicative cannot be used to convey a conjecture, instead). For completeness, we have to mention that the subjunctive can also be used with a non-conjectural reading. Interestingly, in this case, the sentence has a tendency to describe a 'pretend' situation (22), where the attitude holder is not simply imagining, but she is behaving as in a pretend game, with a pretend $N .^{8}$

$$
\begin{aligned}
& \text { Immaginava. che il suo letto fosse un' automobile. } \\
& \text { Imagine.IMPF.3SG that the his bed be.SUBJ.3SG a car. } \\
& \text { He was imagining/pretending that his bed were a car. }
\end{aligned}
$$

As for the starting contrast between indicative-immaginare and subjunctive-immaginare, and generalizing from there, we can see that the pattern emerged for belief replicates here.

(23) Solipsistic-IMAGINE.

All worlds in the imagination space are worlds in which the prejacent is true.

There is no update instruction, requesting to update the negotiation space.

$$
\text { Inquisitive-IMAGINE. }
$$

$p$ is knowable

All worlds in the imagination space are worlds in which the prejacent is true.

\footnotetext{
${ }^{8}$ We thank Ivano Ciardelli for this example.
} 
The speaker does not know whether $p$ is true in the actual situation. UPDATE INSTRUCTION: PRESENT $p$.

\section{Belief and assertion: back to the initial puzzles}

With this distinction between private and public belief, we are now ready to reconsider the initial puzzles in a new perspective, which considers attitudes not only as expressing private commitments as per Hamblin, but also public commitments. By featuring a PRESENT update instruction, and insofar as they manipulate public spaces, public attitudes enter in a complementary distribution with the bare assertion. On the assumption that the illocutionary makeup of a bare assertion is as in (25), we propose that the illocutionary makeup of a belief sentence is as in (26).

Bare assertion of $p$. ASSERT $p$

With the bare assertion, $p$ is added to $N$

\section{ASSERT John believes-PRESENT $p$}

While the higher ASSERT in (26) updates $N$ with the proposition [believe $p$ ], PRESENT is in charge of requesting an update of $N$. When an inquisitive-belief sentence is chosen rather than the bare assertion, a signal is given that $N$ must be updated with a preference for $p$ revealing partial commitment to $p$.

We thus obtain the following picture:

\begin{tabular}{|c|c|c|c|} 
attitude & private space $s$ & negotiation space $N$ & common ground $C$ \\
\hline want & $p>$ non- $p$ & & \\
belief (private) & $p$ & & \\
belief (public) & $p$ & $p>$ non- $p$ &
\end{tabular}

Table 5: Public and private dimensions of the attitudes

Both solipsistic-BELIEF and inquisitive-BELIEF are weaker than assertion when it comes to the negotiation space. Solipsistic-BELIEF does not even request to update that space, and inquisitiveBELIEF requests to update it with a preference for $p$ rather than with $p$ itself.

Considering the contribution to $N$, we thus see that solipsistic-BELIEF and inquisitive-BELIEF differ in informativity. We define informativity as the addition to $N$ at least as strong as a preference for $p$.

Informativity scale.

When added to $\mathrm{N}: p>>[p>$ non- $p]>>[p$ or non- $p]$

Informativity. An utterance is informative iff it adds at least a preference for $p$ in the negotiation space $N$.

Solipsistic-BELIEF is not informative, as it adds nothing to $N$. Inquisitive-BELIEF, on the other hand, is informative, as it adds a preference for $p$ in $N$.

Comparing now bare assertions and belief statements, we can now account for the paradoxes observed in section 1 .

\begin{tabular}{|c|c|c|c|} 
attitude & $s$ & $N$ & $C$ \\
\hline solipsistic belief & $p$ & & \\
inquisitive belief & $p$ & $p>$ non- $p$ &
\end{tabular}




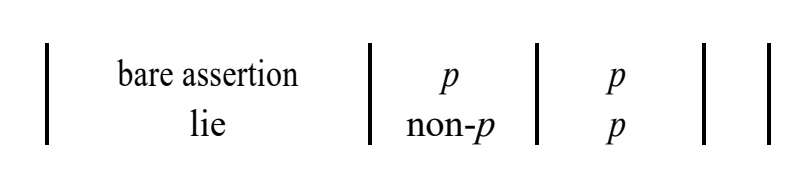

Table 6: Comparison between bare assertion and belief statements

As the table illustrates, there is a variety of combinations of private and public commitments to the truthfulness of $p$. With solipsistic belief, the speaker is only privately, but not publicly committed. With inquisitive/public belief, the speaker is fully privately committed but only partially publicly committed. With sincere bare assertions, he is both privately and publicly fully committed to $p$. With lies he is only publicly fully committed.

We can now see that BELIEVE-statements differ from sincere assertions not in the private dimension but in the public one. The fact that there is no difference between belief statements and assertions in the private dimension explains why belief statements and assertions seem to be mutually entailing, as the data in (2-a)-(2-b) - recalled in (29-a)-(29-b) - reveal.

a. I believe that it rains, \\#but it does not rain.
b. It rains, I\#but I do not believe that it rains.

However, we have also noted in line with the literature that belief statements seem to be weaker than assertions, as the contrast between $(3-a)-(3-b)$ repeated here in $(30-a)-(30-b)$ reveals.

a. It is raining, \#but I am not certain that it is raining.

b. I believe that it is raining, but I am not certain that it is raining.

Assertion and BELIEVE statements differ in their public commitments: while both rely on a full private commitment, with BELIEVE statements the speaker signals that $\mathrm{s} / \mathrm{he}$ is not ready to (fully) publicly commit.

\section{Conclusion}

This paper had the goal of bringing new elements to the debate about the intricacies between belief statements and assertions, a very live debate in philosophy, to which we believe that linguistics can fruitfully contribute. Indeed, we have observed that belief predicates come in two sorts: as private and as public attitudes, and that languages that feature mood choice allow us to see this distinction clearly. From a semantic and, more broadly, a conceptual perspective, languages that do not feature mood choice can also feature these two interpretations; however, they are hardly visible in the absence of grammatical marking.

If our analysis is on the right track, it is possible to tease apart two categories of attitudes, those whereby the speaker intends to contribute to finding truth and those whereby the speaker intends to make her state of mind known. The first are public attitudes, the second private ones. We have used the 'uptake' criterion: only those attitudes that present $p$ for uptake are public. Attitudes that present $p$ for uptake are such that, if $p$ is true, then $p$ becomes common ground. In order to be so, $p$ must be knowable (must be such that a truth value can be assigned to it, in the context of utterance) and only epistemic attitudes can be public, granted absence of future orientation and absence of judgments of personal preference which cannot be verified as true or false objectively in the context of utterance.

Cette recherche est financée par l'ANR-17-EURE-0017 FrontCog ANR-10-IDEX-0001-02 PSL

\section{References}

Anand, Prnav and Hacquard, Valentine. 2013. Epistemics and attitudes. Semantics and Pragmatics 6. $1-59$.

Bach, Kent and M. Harnish, Robert. 1979. Linguistic Communication and Speech Acts. Cambridge, Mass.: MIT Press. 
Castroviejo, Elena (to appear). Exclamatives. To be published in Gutzmann, D., Matthewson, L., C. Meier, H. Rullmann and E. Zimmermann (eds.) Companion to Semantics. Blackwell-Wiley.

Clark, Herbert and Schaefer, Edward. 1989. Contributing to Discourse. Cognitive Science 13. 259294.

Copley, Bridget. 2002. The semantics of the future. PhD MIT.

Farkas, Donka. 1985. Intensional Descriptions and the Romance Subjunctive. New York: Garland.

Farkas, Donka and Bruce, Kim. 2010. On Reacting to Assertions and Polar Questions. Journal of Semantics 27. 81-118.

Frege, Gottlob. 1918. Der Gedanke. Eine logische Untersuchung. Beiträge zur Philosophie des Deutschen Idealismus 2. 1918-1919.

Giannakidou, Anastasia. 1999. Affective dependencies. Linguistics and Philosophy 22(4). $367-421$.

Giannakidou, Anastasia. 2013. Inquisitive assertions and nonveridicality. In M. Aloni, M. Franke, F. Roelofsen (eds.) The dynamic, inquisitive, and visionary life of , ? and possibly - A festschrift for Jeroen Groenendijk, Martin Stokhof and Frank Veltman, 115-126.

Giannakidou, Anastasia and Alda Mari. 2016. Emotive predicates and the subjunctive: a flexible mood ot account based on (non)veridicality. Proceedings of Sinn und Bedeutung 20.

Giannakidou, Anastasia and Mari, Alda 2018. A unified analysis of the future as epistemic modality :

the view from Greek and Italian. Natural Language and Linguistic theory 36. 85-129.

Giannakidou, Anastasia and Mari, Alda (in press). Veridicality in grammar and thought: mood, modality, and propositional attitudes. The University of Chicago Press.

Ginzburg, Jonathan. 2011. A Semantics for Interaction in Dialogue. CSLI Publications.

Giorgi, Alessandra and Pianesi, Fabio. 1996. Tense and Aspect. Oxford: Oxford University Press.

Gosselin, Laurent. 2015. Sémantisme modal du verbe recteur et choix du mode de la complétive. Lexique 22. 223-246.

Gosselin, Laurent. 2016. Les modes expriment-ils des modalités ? L'alternance indicatif / subjonctif dans les complétives objet. Lingvisticae Investigationes 39-1. 145-192.

Gunlogson, Christine. 2001. True to Form: Rising and Falling Declaratives in English. Ph.D. UCSC.

Hamblin, Charles. 1970, Fallacies. London: Methuen.

Hintikka, Jakko. 1962. Knowledge and Belief. Cornell: Cornell University Press.

Homer, Vincent. 2007. Intervention effects: The case of presuppositions. UCLA MA thesis.

Howthorne, John, Rotschild, Daniel and Spectre, Levi. 2016. Belief is Weak. Philosophical Studies 173. 393-1404.

Kaufmann, S. 2005. Conditional Truth and Future Reference. Journal of Semantics. doi: $10.1093 / \mathrm{jos} / \mathrm{ffh} 025$

Krifka, Manfred. 2015. Bias in Commitment Space Semantics: Declarative questions, negated questions, and question tags. Proceedings of SALT 25. 328-345.

Lasersohn, Peter. 2005. Context dependence, disagreement, and predicates of personal taste.

Linguistics and Philosophy 28(6). 643-686.

Lauer, Sven. 2013. Towards a dynamic pragmatics. PhD Stanford.

Mari, Alda. 2015. Modalités et Temps: des modèles aux données. Peter Lang.

Mari, Alda. 2016. Assertability conditions of epistemic (and fictional) attitudes and mood variation. Proceedings of SALT 26. 61-81.

Mari, Alda. 2017. Belief and assertion. Belief and assertion. Evidence from mood shift. Workshop Questioning Speech Acts. Kostanz, September 14-16.

Mari, Alda and Portner, Paul. 2019. Mood variation with belief predicates: Modal comparison in semantics and the common ground. Ms. IJN and Georgetown University.

MacFarlane, John. 2005. Future Contingents and Relative Truth. The Philosophical Quarterly 53. 321-336.

Patard, Adeline and Walter de Mulder. 2016. Le développement du subjonctif après les verbes de sentiment. Talk at Tam-e Conference. Paris.

Portner, Paul. 2018. Mood. Oxford: OUP.

Portner, Paul. 2007. Beyond the Common Ground: The Semantics and Pragmatics of Epistemic Modals. In Jong Yurl Yoon and Kyoung Ae Kim (eds.), The Perspectives of Linguistics in the 21st Century, 1-18. Seoul: Hankook Munhwasa. 
Portner, Paul and Aynat Rubinstein. 2013. Mood and contextual commitment. In Anca Cherches (ed.), Semantics and Linguistic Theory (SALT) 22. 636-659. Ithaca, NY: CLC.

Quer, Joseph. 1998. Moods at the interfaces. Utrecht: OTS PhD dissertation.

Rhis, Alain. 2013. Subjonctif, gérondif et participe présent en français: une pragmatique de la dépendance verbale. Bern: Peter Lang.

Roberts, Craige. 1996/2012. Information structure and discourse: Towards an integrated theory of formal pragmatics. Semantics and Pragmatics 5. 1-69.

Stalnaker, Robert. 1978. Assertion. In Peter Cole (ed.) Pragmatics (Syntax and Semantics 9), 315-332. New York: NY Academic Press.

Stephenson, Tamina. 2007. Judge dependence, epistemic modals, and predicates of personal taste. Linguistics and Philosophy 30(4). 487-525.

Thomason, Richmond 1984. Combination of Tense and Modality, in D. Gabbay; F. Guenthner (eds.), Handbook of Philosophical Logic: Extensions of Classical Logic, 135-165. Dordrecht: Reidel,

Veltman, Frank. 2006 Defaults in update semantics. Journal of Philosophical Logic 25. 221-261.

Villalta, Elisabeth. 2008. Mood and gradability: an investigation of the subjunctive mood in Spanish. Linguistics and Philosophy 31(4). 467-522. 